Purdue University Purdue e-Pubs

$1-1-1982$

\title{
Calibration Procedures for Measurement of Reflectance Factor in Remote Sensing Field Research
}

\author{
B. F. Robinson \\ L. L. Biehl
}

Follow this and additional works at: http://docs.lib.purdue.edu/larstech

Robinson, B. F. and Biehl, L. L., "Calibration Procedures for Measurement of Reflectance Factor in Remote Sensing Field Research" (1982). LARS Technical Reports. Paper 93.

http://docs.lib.purdue.edu/larstech/93

This document has been made available through Purdue e-Pubs, a service of the Purdue University Libraries. Please contact epubs@purdue.edu for additional information. 


\section{CALIBRATION PROCEDURES FOR MEASUREMENT OF REFLECTANCE FACTOR IN REMOTE SENSING FIELD RESEARCH}

\author{
B,F, ROBINSON, L, L, BIEHL \\ Purdue University/Laboratory for \\ Applications of Remote Sensing \\ West Lafayette, Indiana
}

\section{Abstract}

A means by which measurements of the optical properties of crops and soils can be knowledgeably compared from site to site and instrument to instrument is presented in detail. The definition of bidirectional reflectance factor is reviewed and discussed. Procedures for field implementation are illustrated and discussed. Spectral and goniometric properties of laboratory and field reference surfaces are given. It is concluded that intelligent use of the bidirectional reflectance factor technique is an accurate and practical means to obtain the spectral, optical properties of crops and soils needed for advancements in agricultural remote sensing.

\section{Introduction}

The use of optical radiation for the indentification and quantification of agricultural crops from earth satellites has reached near operational status for some crops. 1,2 As the technology develops there is a growing awareness of the need for understanding the optical properties of crops and soils.

Researchers are heading to the fields in increasing numbers with a variety of instruments to measure radiation reflected and emitted by soils and crop canopies. While many types of measurements will prove to be useful, there is a need for data which may be compared from site to site and instrument to instrument, independent of atmospheric conditions.

The purpose of this paper is to describe and discuss a calibration procedure which has been used since 1974 by the Purdue University Laboratory for Applications of Remote Sensing and the Field Research Program of the Earth Observations Division, NASA, Johnson Space Center ${ }^{3}$ to obtain measurements which are being analyzed across sites and instruments in on-going agricultural experiments.

Bidirectional Reflectance Factor (BRF) A reflectance factor is defined as the
ratio of the radiant flux actually
reflected by a sample surface to that
which would be reflected into the same
reflected beam geometry by an ideal (loss-
less) perfectly diffuse (Lambertian) stan-
dard surface irradiated in exactly the
same way as the sample.

The essential field calibration procedure consists of the comparision of the response of the instrument viewing the subject to the response of the instrument viewing a level reference surface. For small fields of view (less than $20^{\circ}$ full angle) the term bidirectional reflectance factor has been used to describe the measurement: one direction being associated with the viewing angle (usually $0^{\circ}$ from normal) and the other direction being the solar zenith and azimuth angles.

The true bidirectional reflectance fac$\operatorname{tor}^{4} \mathrm{R}\left(\theta_{i}, \phi_{i} ; \theta_{r}, \phi_{r}\right)$ is defined for incident and reflected beams where $\left(\theta_{i}, \phi_{i}\right)$ and $\left(\theta_{r}, \phi_{r}\right)$ are the zenith and azimuth angles of the incident beam and reflected beam, respectively.

The essential field calibration procedure consists of the measurement of the response, $V_{S}$, of the instrument viewing the subject and measurement of the response, $V_{r}$, of the instrument viewing a level reference surface to produce an approximation to the bidirectional reflectance factor of the subject.

$$
R_{S}\left(\theta_{i}, \phi_{i} ; \theta_{r}, \phi_{r}\right)=\frac{V_{S}}{V_{r}} R_{r}\left(\theta_{i}, \phi_{i} ; \theta_{r}, \phi_{r}\right)
$$

where $R_{r}\left(\theta_{i}, \phi_{i} ; \theta_{r}, \phi_{r}\right)$ is the bidirectional 
reflectance factor of the reference surface. $R_{r}$ is required to correct for its non-ideal reflectance properties.

The assumptions are:

(1) The incident radiation is dominated by its directional component.

(2) The instrument responds 1 inearly to entrant flux.

(3) The reference surface is viewed in the same manner as the subject and the conditions of illumination are the same.

(4) The entrance aperture is sufficiently distant from the subject and the angular field of view is small with respect to the hemisphere of reflected beams. For our purposes a $20^{\circ}$ angular field of view is about the limit for this assumption.

(5) The reflectance properties of the reference surface are known.

For multiband radiometers the reflectance factor results from the response of the instrument to the radiance of the subject and the reference in each effective passband and, therefore, is an in-band reflectance. For spectroradiometers the spectral bidirectional reflectance factor is computed at each resolved wavelength.

\section{Discussion of the Approach}

The objective of the approach is to obtain a property of the scene which is nearly independent of the incident irradiation and atmospheric conditions at the time of the measurement. The majority of measurements are made by viewing along the normal to the subject and the level reference surface with solar angles similar to the conditions of satellite overpass. Under these conditions, the properties of the subject are measured which affect the response of the satellite-borne sensor.

If the researcher desires, the irradiance and the directional radiance of the subject may be determined from the raw data provided the instrument is calibrated. The estimation of these quantities usually involves a high degree of uncertainty and, fortunately, it is not necessary to know them to compute the reflectance factor.
An understanding of the factors which affect the bidirectional reflectance factor of agricultural scenes will provide a basis for improved identification and quantification of agricultural crops. A deeper understanding will be required in the future with the advent of improvements in characterizing the optical properties of the atmosphere over frames of satellite-borne sensor data and future satellite sensors which view the surface at angles significantly different from normal.

\section{Field Procedures}

The field procedure for reflectance factor calibration will vary with the instrument system depending mainly on the means used to support the instrument above the crop. The principle is, as nearly as possible, to measure the level reference surface with the same conditions of irradiation and viewing as the crop was measured. For example, Figure 1 shows a multiband radiometer mounted on a pick-up truck mounted boom viewing a soybean canopy. When viewing the crop, at a

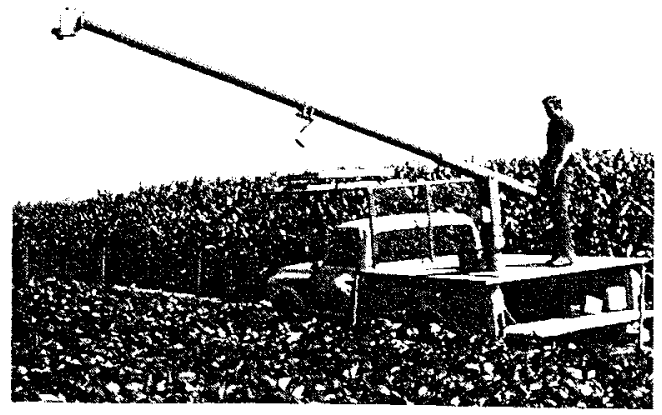

Eigure 1. Truck-mounted multiband radiometer viewing a soybean canopy.

height of 4.2 meters, the diameter of the $15^{\circ}$ field of view is 1.1 meters. Figure? shows the boom rotated for the calibration operation. To ensure filling the field of view during the calibration operation, the instrument is positioned at a height of about 2 meters above the 1.2 meter square painted barium sulfate reference panel. At this distance, the diameter of the field of view, 0.5 meters, can be confidently located on the painted reference surface. For this mounting technique, the time from the nearest calibrations is about 8 minutes. Reference surface data is interpolated to compute inband reflectance factors for each of the 15 plots which were measured (twice) during the interval. 


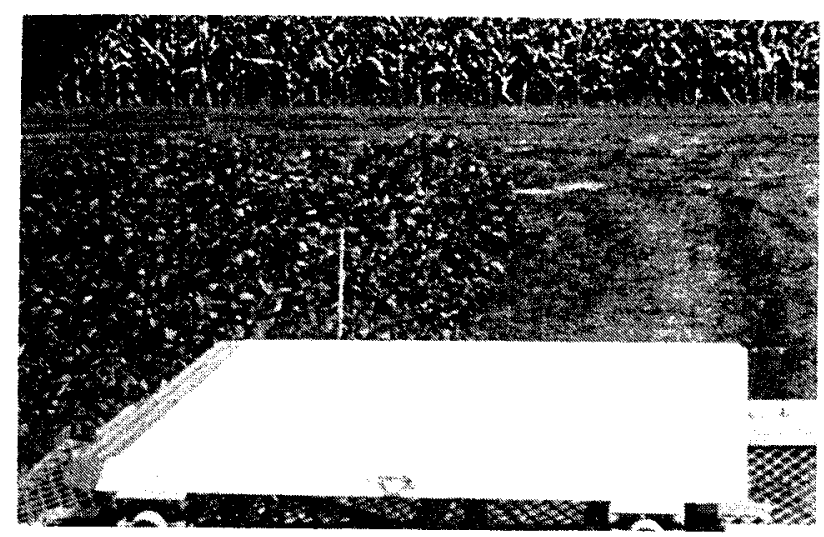

Figure 2. Multiband radiomeier positioned over painted barium sulfate reference panel for field reflectance calibration.

Reference Surfaces

As listed above, an assumption for measuring BRF is that the reflectance properties of the reference surface are known. Three kinds of reference surfaces have been used by Purdue/LARS and NASA/JSC for field research. They are pressed barium sulfate powder, ${ }^{5,6}$ painted barium sulfate, and canvas. The canvas reference surfaces are about 6 by 12 meters and are painted with a durable, diffuse paint. The nominal reflectance of the canvas panel is around 60 percent. All three reference surfaces are highly diffuse (for the solar angles encountered) and have medium to high reflective properties. Each of the reference surfaces were used to meet the requirements for a given instrumentation system. The spectral bidirectional reflectance factor for the three reference surfaces are illustrated in Figure 3 .

Figure 4 illustrates the gonimetric properties of the three reference surfaces from 5 to 55 degrees off normal at $.6 \mu \mathrm{m}$. The spectral goniometric properties of painted barium sulfate and canvas are shown in Figures 5 and 6 , respectively. The BRF calibration transfer for the reference surfaces is illustrated in Figure 7 .

Pressed barium sulfate is primarily used an an indoor laboratory standard to calibrate the field painted barium sulfate reference surfaces. The pressed barium sulfate is used at incident angles of 10 degrees off normal in the indoor laboratory setup. ${ }^{8} \quad$ Painted barium sulfate panels are used as the reference surfaces for truck-mounted spectrometer/multiband radiometer systems. The canvas panel is used as the reference surface for a helicopter-mounted spectrometer system.

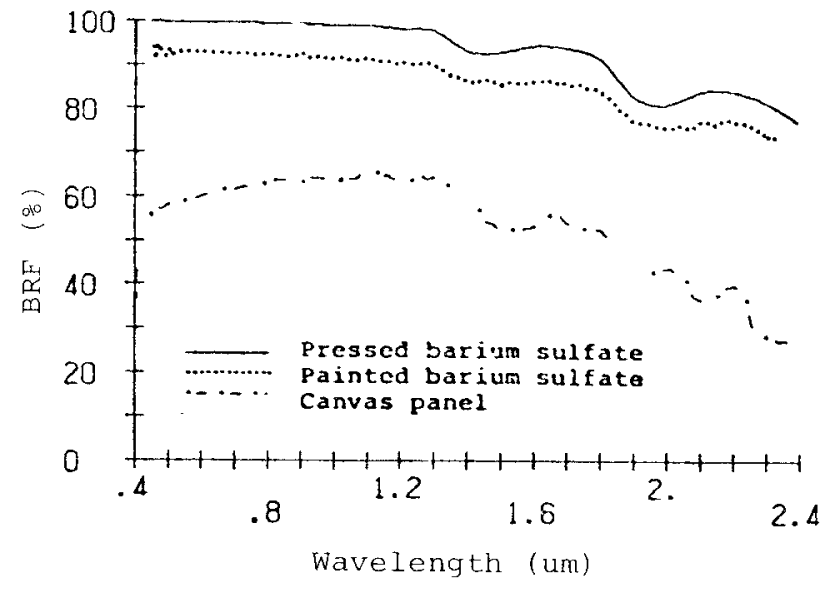

Figure 3. Spectral bidirectional reflectance factor of three reference surfaces used for field research.

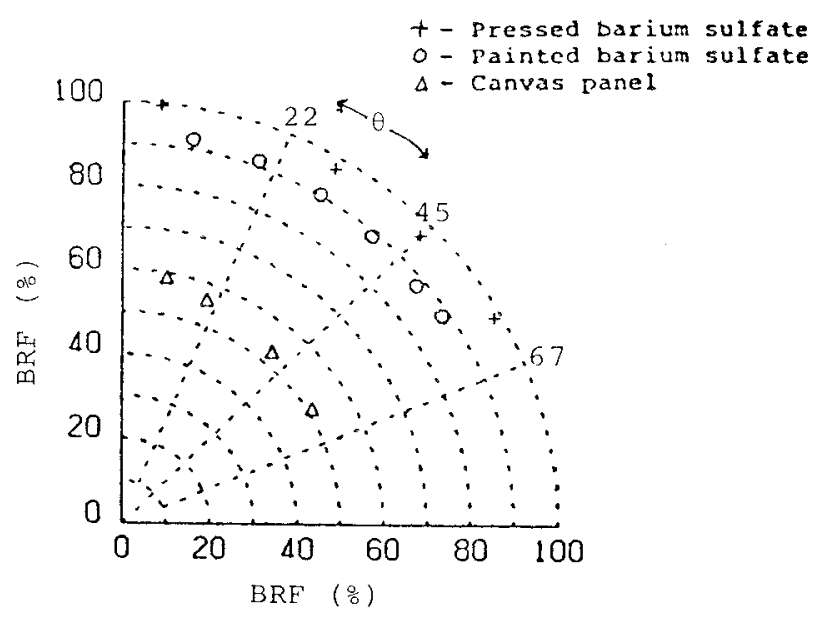

Figure 4. Bidirectional reflectance factor at $.6 \mathrm{um}$, for several incident angles and reference surfaces. Polar coordinates.

Effects of Non-Directional Illumination

An assumption for the measurement of $\mathrm{BRF}$ is that the incident radiation is directional. Clouds and skylight cause the irradiance of the subject and reference surface to be other than directional. Clouds can (theoretically) be avoided by taking data on clear days. Skylight, however, can not be avoided. 


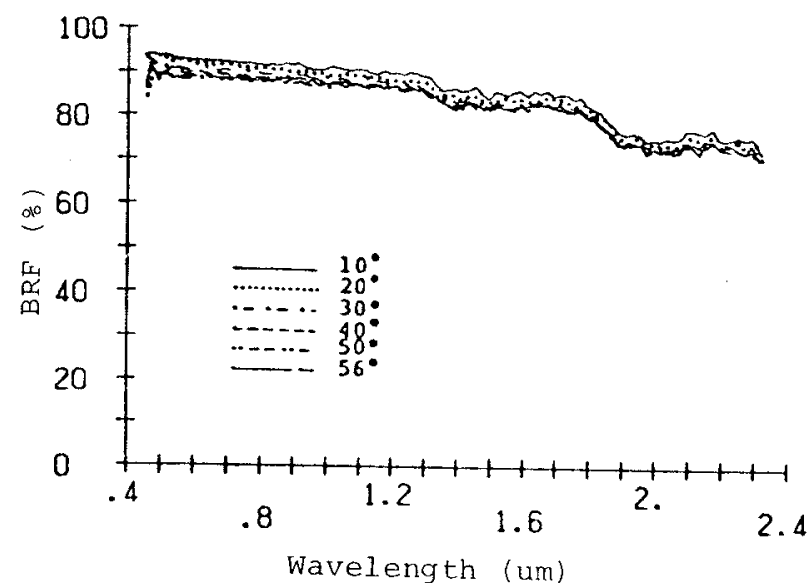

Figure 5. Spectral bidirectional reflectance factor of painted barium sulfate for several incident angles (view angle is normal).

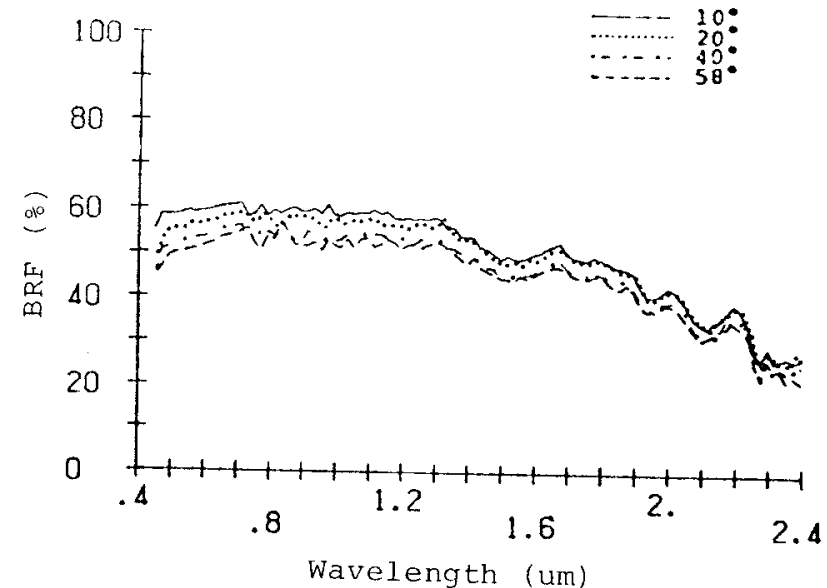

Figure 6. Spectral bidirectional reflectance factor of a canvas panel for several incident angles (view angle is normal).

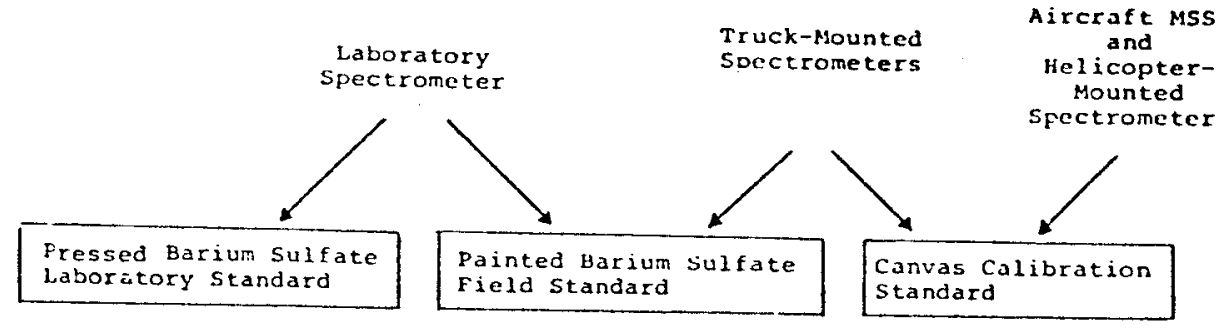

Figure 7. Bidirectional reflectance factor calibration transfer of reference surfaces used for agricultural field research.

The effects of skylight and clouds have been discussed in detail by Robinson \& Biehl' and recently expanded by Kirchner, Youkhana, and Smith.10

Recognizing that Equation 6 in Robinson \& Bieh ${ }^{9}$ is limited to viewing along a normal to the subject, Kirchner, Youkhana, and Smith extended Equation 6 to

$$
R_{F}=R_{t}\left(\theta_{i}, \phi_{i} ; \theta_{r}, \phi_{r}\right)\left|1+K_{1} \cdot K_{2}\right|
$$

where $K_{l}$ is a function of the solar and observation angle and $\mathrm{K}_{2}$ is a function of the solar angle. They, then applied Equation (2) using a variety of modelled canopies and sky radiances which were uniformly and non-uniformly distributed. The errors introduced by the skylight were less than $5 \%$ of value for solar and view angles less than $55^{\circ}$ for clear days.

However, the authors ${ }^{10}$ caution against experimental error introduced by large, brightly reflecting clouds.

Comparison of BRF Measurements made by Three Spectrometer systems

During the Large Area Crop Inventory Experiment (LACIE), 1,3 four different spectroradiometer systems were used to collect agricultural field spectral BRF measurements. The spectroradiometer systems were used in five different test sites in North Dakota, South Dakota and Kansas. Common scenes, canvas panels, were transported between the test sites to be used for the reflectance calibration of a helicopter mounted spectrometer and if researchers desire - aircraft scanner data. In July of 1977, three of the spectroradiometer systems were brought together to the Williams County, North Dakota test site for a formal comparison study. 
The results of the instrument comparison study presented in Robinson \& Biehl" indicate that the procedure developed for the measurement of BRE is sound. Moreover, quantitative information about the comparison of the measurements from different spectroradiometer systems is available. The use of common scenes such as canvas panels is a valuable aid in accessing the comparability of several spectrometer systems. The comparison can be done by bringing the systems together as was done for the above study or by transferring the common scenes from site to site.

\section{Conclusions}

Bidirectional reflectance factor (BRF) is an appropriate and useful optical property for remote sensing field research because it is a fundamental property of the subject. The described procedures for use of reflectance surfaces provide a good approximation to the true $B R F$ of the subject because the irradiance is dominated by its directional component, the reference surface is nearly Lambertian and the BRF of the subject is not radically different from Lambertian.

The described procedure is an effective means to acquire data which may be meaningfully compared from time to time, site to site, and instrument to instrument because:

- It is relatively easy to train instrument operators to obtain repeatable results.

- The reference surfaces can be prepared and tested at central locations; therefore, most researchers do not need sophisticated calibration apparatus.

- The performance of different instruments can be easily compared under field conditions.

Acquisition of meaningful data requires that measurements be made at the appropriate scale. This entails positioning the sensor at a proper distance above the subject, and careful consideration of the field of view. Without careful planning, these factors and other procedural errors can seriously limit the usefulness of well calibrated data.

\section{Acknowledgement}

The authors wish to thank Professor David P. DeWitt and Professor L.F. Silva of Purdue University and Dr. David E.
Pitis and Mr. Richard Juday of NASA/Johnsor space Center for their advice and helpful discussions. The research work leading to this paper was performed under NASA Contract Number NAS9-15466.

Referues

1. MacDonald, R. B. and F. G. Hall. Global Crop Forecasting. Science 208:670-679. 1980 .

2. Landgrebe, D. A., "Monitoring the Earths Resources from Space - Can You Really Identify Crops by Satellite?", AEIPS Conference Proceedings", Vol. 48, $\mathrm{pp} \cdot 233-241$, AFIPS Press, Montvale, N 07645,1979 .

3. Bauer, M. E., M. C. McEwen, W. A. Malila and J. C. Harlan. $1978^{\circ}$ Design, Implementation and Results of LACIE Field Research. Proc. LACIE Symposium, NASA Johnson Space Center, Houston, Texas, Oct. 23-26, pp. 1037-1066 (JSC-16015).

4. Nicodemus, F. E., et al., Geometrical Considerations and Nomenclature for Reflectance. NBS Monograph 160, U.S. Govt. Printing office, Washington, D.C. 20402 , October 1977.

5. Gram, F. and G. W. Luckey, "Optical Sphere Paint and a Working Standard of Reflectance," Applied Optics, Vol. 7, No. 11 , pp. 2289-2294, November 1978 .

6. Billmeyer, F. W., Jr., D. L. Lewis and James G. Davidson, "Goniometry of Pressed Barium Sulfate," Color Engineering, May-June 1971 .

7. Shai, C. M. and J. B. Schutt, "Formulation Procedure and Spectral Data for Highly Reflecting Coating From $200 \mathrm{~nm}$ to 2300 nm", Doc. X-762-71-266, NASA, Goddard Space Center, Greenbelt, MD, July 1971 .

8. Dewitt, D. P. and B. F. Robinson, Description and Evaluation of a Bidirectional Reflectance Factor Reflectometer, Purdue/LARS Tech. Report 091576, Purdue University, Laboratory for Applications of Remote Sensing, September 1976.

9. Robinson, B. F. and L. L. Biehl. Calibration Procedures for Measurement of Reflectance Factor in Remote Sensing Field Research. SPIE Vol. 196, pp. 16-26, Measurements of Optical Radiation. 1979 . 
10. Kirchner, J. A., S. Youkhana, and J. A. Smith, "Influence of Sky Radiance Distribution on the Ratio Technique for Estimating Bidirectional Reflectance Factor", Photogrammetric Engineering. 1982.

In Press.

Author Biographies

Barrett F. Robinson, senior research engineer and Associate Program Leader of te Measurements Program Area at LARS, has B.S. and M.S. degrees in electrical engineering and mathematics from purdue University. He participated in the design and has directed the implementation and operation of the field spectroradioneter system used by purdue/LARS to acquire calibrated digital spectral data. He had a key role in the NASA LACIE Field Measurements project in defining and directing the spectral data acquisition by Purdue and NASA/JSC. He has been responsible for the development of a multiband radiometer for field research and has directed its procurement and training and coordination of users during 1981 .

Larry L. Biehl, research engineer in the Measurements Program Area at LARS, has a B.S. degree in electrical engineering and an M.S. degree in engineering from Purdue University. He has had roles in NASA's Skylab program as a data analyst, NASA's Thematic Mapper study as project manager and analyst, the LACIE Field Measurements Project, and currently the AgRISTARS Supporting Research Project. His present roles include overseeing spectral data acquisition, calibration and correlation, coordinating entry of the field research data into the library and developing improved software for more efficient analysis of spectral data. Mr. Biehl is a member of IEEE. 